\title{
A institucionalização da agricultura familiar no Mercosul: da definição normativa aos sistemas nacionais de registro
}

\author{
Institutionalization of family farming in Mercosur: from normative \\ definition to the national systems of registration
}

Paulo Andre Niederle - Professor dos programas de pós-graduação em Sociologia (PPGS) e em Desenvolvimento Rural (PGDR) da Universidade Federal do Rio Grande do Sul (UFRGS). Doutor em Ciências Sociais (CPDA/UFRRJ). E-mail: pauloniederle@gmail. com

\section{Resumo}

Analisa o processo de institucionalização da agricultura familiar nos países do Mercosul. O foco volta-se para a ação da Reunião Especializada sobre Agricultura Familiar (REAF), um fórum multilateral que se tornou o principal espaço de diálogo entre governos e movimentos sociais para o desenho de políticas de desenvolvimento rural em âmbito regional. A partir de análise documental, observação dos diálogos e entrevistas com gestores públicos e lideranças sociais, o artigo demonstra como a REAF coordenou um processo de harmonização dos quadros normativos que definem, identificam e tipificam a agricultura familiar. Ao mesmo tempo, analisa as controvérsias que cercaram a redação de uma definição comum e os desafios relacionados à operacionalização dos Sistemas Nacionais de Registro. Os resultados apontam ainda para o protagonismo do Brasil neste processo, mas também para as readequações institucionais operadas pelos demais países, o que retroalimenta discussões sobre a pertinência de alterações normativas no próprio contexto brasileiro.

\section{Palavras-chave}

Agricultura Familiar. Mercosul. Normatização. Desenvolvimento Rural.

\begin{abstract}
This paper analyzes the process of institutionalization of family farming in the Mercosur. The main attention is on the action of the Specialized Meeting on Family Agriculture (REAF), a multilateral forum that has become a privileged arena of dialogue between government and social movements for the construction of rural development policies at the regional level. From document analysis, observation of the dialogues and interviews with policy makers and social leaders, the paper demonstrates how REAF has coordinated a process of harmonization of the regulatory frameworks that are used to define, identify and typify the family farm. At the same time, it analyses the controversies involved in the construction of a common definition for family farming and the challenges related to the implementation of the National Registration Systems. The results point also to the key role played by Brazil in the leadership of this process but also for institutional readjustments operated by the other countries, which support a discussion about the pertinence of normative changes in the Brazilian context.
\end{abstract}

\section{Keywords}

Family Farming. Mercosul. Normalization. Rural Development. 


\section{INTRODUÇÃO}

Há uma década a agricultura familiar tornou-se objeto de uma definição comum nos países do Mercosul (Resolução CMC nํ 25/2007). A construção desta definição foi resultado de um complexo diálogo político entre governos e movimentos sociais, os quais ocorreram, principalmente, no âmbito da Reunião Especializada de Agricultura Familiar (REAF), um fórum multilateral criado em 2004 e que, desde então, tem cumprido um papel relevante na formulação, desenho e implementação de políticas de desenvolvimento rural nos países do bloco. O objetivo deste artigo é analisar o processo de construção da definição, a institucionalização dos instrumentos normativos e a implantação dos Sistemas Nacionais de Registro, os quais constituem os mecanismos por meio dos quais os Estados identificam o público específico a ser alcançado pelas políticas diferenciadas para a Agricultura Familiar.

De modo geral, dois desafios principais se interpõem a este tipo de processo de reconhecimento e institucionalização. O primeiro refere-se à existência prévia de outras definições, as quais implicam em algum grau de irreversibilidade institucional ou "path dependence" (MAHONEY, 2001). Ou seja, na medida em que os países já contavam com conceitos e parâmetros próprios, a adoção de uma normativa regional torna-se um processo delicado de rearranjo das estruturas institucionais, o que implica tanto em manejar as identidades sociais existentes, quanto na redefinição dos beneficiários das políticas públicas - tornando-se passível, por ambas as razões, de forte contestação social. O segundo desafio é o manejo da heterogeneidade. Definições muito rígidas tendem a excluir vários segmentos sociais e acentuar as assimetrias. Por outro lado, definições excessivamente flexíveis pecam por se tornarem instrumentos inócuos, incapazes de classificar o mundo e orientar a ação pública.

Estes dois desafios estiveram presentes nas discussões sobre a agricultura familiar no Mercosul. Mas a existência de uma definição comum sugere que foi possível construir os entendimentos necessários para superá-los. Como argumentaremos neste artigo, a REAF cumpriu um papel de destaque neste processo, mediando as diferenças, salientando as similaridades e construindo uma agenda positiva, a qual levou os países (governos e movimentos sociais) a dialogar em torno de parâmetros mínimos que permitissem avançar na caracterização, quantificação e suporte público a este segmento social. Também analisaremos como a experiência brasileira de reconhecimento da agricultura familiar constituiu um esteio para os diálogos. Os resultados sugerem que, longe de se impor como um padrão a ser transferido, ela foi objeto de readequações. A definição regional 
não apenas permite aos países manejarem suas diferenças, como trás à tona questões que não haviam sido incorporadas na legislação brasileira.

A investigação foi conduzida a partir da observação de encontros da REAF em 2014 e 2015, pesquisa documental (leis, normas, regulamentos, resoluções etc.), além de 42 entrevistas, conduzidas com ministros, gestores públicos, lideranças sociais, pesquisadores e consultores dos Estados Membros (Argentina, Brasil, Paraguai, Uruguai e Venezuela) e Associados (Bolívia, Chile, Colômbia, Equador e Peru) ${ }^{1}$. Além desta introdução, o artigo está estruturado em quatro seções. A primeira apresenta a estrutura de funcionamento da REAF e os principais debates que marcaram o reconhecimento institucional da agricultura familiar no Mercosul. A segunda discute os instrumentos normativos que foram institucionalizados nos países e suas implicações do ponto de vista da caracterização e quantificação deste segmento social. Em seguida, a terceira seção analisa o processo de construção dos Sistemas Nacionais de Registro, bem como as questões implicadas no reconhecimento mútuo dos mesmos entre os países do bloco. As considerações finais destacam os principais resultados e os desdobramentos da pesquisa.

\section{A REAF E A INSTITUCIONALIZAÇÃO DA AGRICULTURA FAMILIAR NO MERCOSUL}

A Reunião Especializada sobre Agricultura Familiar (REAF) é um fórum de diálogos políticos entre governos e movimentos sociais cuja finalidade é fortalecer as políticas de desenvolvimento rural no espaço regional. Assim como as demais reuniões especializadas do Mercosul, a REAF é um órgão auxiliar do Grupo Mercado Comum (GMC), instância executiva do Conselho do Mercado Comum (CMC), o qual é o espaço supremo de decisões do bloco. Sendo assim, as deliberações da REAF constituem propostas que necessitam a chancela do GMC/CMC. Quando acatadas, elas tornam-se instrumentos normativos que orientam as ações dos Estados Membros e Associados. Dentre estes instrumentos, as Decisões, Resoluções e Diretrizes possuem caráter obrigatório para os Estados Membros. Já as Recomendações são incorporadas voluntariamente (REAF, 2006).

A Plenária Regional é a principal instância de deliberação da REAF (realizada bianualmente). Mas a estrutura organizacional abarca ainda encontros das Seções

1 O autor agradece a colaboração da Secretaria Técnica da REAF, da FAO América Latina e Caribe, e da Assessoria de Relações Internacionais do Ministério do Desenvolvimento Agrário (MDA). Detalhes acerca da metodologia e dos resultados apresentados podem ser encontrados em um Documento Técnico mais extenso sobre a trajetória da REAF, o qual será disponibilizado no site da FAO América Latina e Caribe. 
Nacionais, que são essenciais do ponto de vista político e metodológico (RAMOS et al., 2014). Nestes espaços os atores estatais e não estatais de cada país debatem a pauta com vistas a orientar a intervenção das delegações nacionais escolhidas para a Plenária Regional. Além disso, os Grupos Temáticos são importantes para dinamizar as discussões em torno de temas prioritários, e são igualmente formados por delegados escolhidos nas Seções Nacionais (incluindo um "Ponto Focal" que responde pelo país junto a cada grupo). Atualmente, a REAF abriga cinco GT: (i) Políticas fundiárias, acesso à terra e reforma agrária; (ii) Facilitação do comércio; (iii) Equidade de gênero; (iv) Gestão do risco e mudança climática; e (v) Juventude Rural.

No que tange especificamente à discussão sobre a definição e identificação da agricultura familiar, esta foi inicialmente capitaneada pelo GT Facilitação de Comércio. Tratava-se de um ponto de estrangulamento para projetar políticas diferenciadas de acesso aos mercados. Com efeito, foi a partir dos debates deste GT que a REAF construiu o Projeto de Resolução "Diretrizes para o Reconhecimento e Identificação da Agricultura Familiar no Mercosul”, o qual foi aprovado na VII Plenária Regional (Assunção, maio de 2007) e, posteriormente, ratificado pela Resolução GMC no $25 / 2007$. Esta se tornaria, a partir de então, o principal balizador para todas as ações da REAF.

O próximo passo deste GT seria a construção dos Registros Nacionais Voluntários da Agricultura Familiar. No entanto, em face da demanda de trabalho que esta ação passou a demandar, ela foi redirecionada para um Grupo Técnico específico, o qual possuía caráter temporário, mas, desde a XVII Plenária Regional (Buenos Aires, junho de 2012), se tornou permanente. Foi neste GT que a REAF gestou o Projeto de Decisão sobre os "Registros Nacionais Voluntários da Agricultura Familiar", aprovado na XVIII Plenária Regional (Caxias do Sul, novembro de 2012) e referendado no mesmo ano pela Decisão CMC 59/2012. Desde então, os esforços voltaram para um Projeto de Recomendação que trata do reconhecimento mútuo dos registros, o que implica em cada país reconhecer os agricultores familiares identificados pelos demais. Isto foi aprovado por meio da Decisão CMC nº 20/2014, a qual incorpora ainda procedimentos e rotinas de monitoramento dos registros.

A aprovação da Resolução GMC nº 25/2007 foi um marco na história do Mercosul. Ela corroborou o reconhecimento de uma categoria específica de agricultores que demandavam um olhar diferenciado do Estado e da Sociedade. Ao mesmo tempo, contrariou a ideia outrora acolhida por alguns governos de que em seus países "existia uma única agricultura", o que geralmente resultava no privilégio concedido aos setores do agronegócio (RIELLA, 2002). Com efeito, 
a partir do momento em que o Mercosul formaliza o reconhecimento a esta categoria por meio de uma Resolução de caráter compulsório, os países não tiveram outra alternativa senão identificar as formas específicas de produção, gestão e trabalho que tem como fundamento a estrutura e a dinâmica das famílias, atentando aos critérios definidos regionalmente, a saber:

Art. 1 - Os agricultores/as destinatários das políticas públicas diferenciadas dirigidas ao setor da agricultura familiar serão aqueles cujos estabelecimentos cumpram, no mínimo, todos e cada um dos seguintes critérios:

I) a mão-de-obra ocupada no estabelecimento corresponderá predominantemente à família, sendo limitada a utilização de trabalhadores contratados;

II) a família será responsável direta pela produção e gestão das atividades agropecuárias; e residirá no próprio estabelecimento ou em uma localidade próxima;

III) os recursos produtivos utilizados serão compatíveis com a capacidade de trabalho da família, com a atividade desenvolvida e com a tecnologia utilizada, de acordo com a realidade de cada país.

São também parte da agricultura familiar, desde que respeitados os critérios enumerados acima, os produtores/as rurais sem terra e os beneficiários/as dos processos de reforma agrária ou programas de acesso e permanência na terra, bem como as comunidades de produtores/as que fazem uso comum da terra (Mercosul/GMC/Resolução no 25/2007).

Note-se que os critérios estabelecidos foram mínimos, na medida em que deveriam permitir uma intervenção equitativa entre os países membros, sem descuidar a heterogeneidade que marca a presença destes grupos nos territórios rurais. Como destaca um ator-chave no processo de construção da REAF,

Eu creio que a virtude da definição de agricultura familiar que fez a REAF é que ela é muito pragmática e muito política, e que pode ser adaptável e adaptada a distintas circunstâncias e a distintos países ou regiões. Porque ela define uma série de cinco ou seis características que tem que cumprir a agricultura familiar e deixa livre a ponderação e a parametrização das mesmas à realidade de cada país e de cada região. Isso permite ter uma grande definição guarda-chuva ou compreensiva e, por outro lado, abre a possibilidade de reconhecer a heterogeneidade dentro deste grande conceito (Ex-Secretário Técnico da REAF. Entrevista concedida em março de 2015).

A Resolução foi pautada pelas normas já existentes em alguns países, abarcando, centralmente, a unidade entre gestão e trabalho familiar. Somam-se a isso critérios relacionados à contratação de mão de obra externa e ao local de resistência da família. Mas, para além disto, ela é inovadora ao estabelecer a 
compatibilidade dos recursos produtivos com a capacidade de trabalho familiar, com a atividade desenvolvida e com a tecnologia utilizada, critérios de difícil aferição e que ainda estão sendo incorporados pelos países. Ademais, é importante notar que a norma regional reproduziu a estratégia já presente na lei brasileira (Lei no 11.326/2006) no que diz respeito à incorporação de outros segmentos sociais que não possuem acesso à terra ou fazem uso coletivo da mesma, assim como dos assentados de reforma agrária.

Como destacam Ramos et al. (2014), esta resolução demarca uma mudança de paradigma no que diz respeito à compreensão do lugar e do papel das formas familiares de produção nos países do Mercosul. Ainda que a trajetória de reconhecimento da agricultura familiar já tivesse avançado no Brasil (GRISA; SCHNEIDER, 2015; PICOLOTTO, 2014), nos demais países do bloco este segmento ainda se encontrava relegado à representação de uma "pequena agricultura", marginal e incapaz de constituir uma via para o desenvolvimento rural. De outro modo, ao longo dos últimos dez anos, a agricultura familiar começou a ser tratada como porta-voz dos modelos mais inovadores de desenvolvimento rural sustentável, o que implicou na construção de políticas públicas. Atualmente, a ampla maioria dos países do bloco conta com instrumentos especificamente direcionados para esta categoria social.

No Brasil, desde meados dos anos 1990 vem sendo criadas institucionalidades e instrumentos de políticas públicas para a promoção da agricultura familiar. Dentre os principais exemplos estão o Programa Nacional de Fortalecimento da Agricultura Familiar (PRONAF), a Declaração de Aptidão ao Pronaf (DAP), a Lei da Agricultura Familiar, o Programa de Aquisição de Alimentos (PAA), o Seguro da Agricultura Familiar (SEAF), o Conselho Nacional de Desenvolvimento Rural Sustentável (CONDRAF), o Programa Garantia Safra, o Selo da Agricultura Familiar e o Programa de Garantia de Preço da Agricultura Familiar (PGPAF). Como destacam Grisa e Schneider (2015), ao longo dos últimos vinte anos o Estado brasileiro consolidou uma complexa arquitetura de políticas públicas, sugerindo um esforço para tornar a agricultura familiar um segmento estratégico à economia nacional, à segurança e soberania alimentar e ao desenvolvimento social.

$\mathrm{Na}$ Argentina, a denominação "agricultura familiar" começou a aparecer na agenda do Estado em 2004. Dentre o conjunto de eventos que marcam este processo destaca-se: a organização do Fórum Nacional da Agricultura Familiar (FONAF); a construção de critérios que distinguem a agricultura familiar dos pequenos empresários agropecuários ou agroindustriais; a criação da Secretaria de Desenvolvimento Rural e da Agricultura Familiar vinculada ao Ministério 
da Agricultura, Pecuária e Pesca; o estabelecimento do Registro Nacional da Agricultura Familiar (RENAF); a formulação do Programa Nacional de Investigação e Desenvolvimento Tecnológico para a Pequena Agricultura Familiar (CIPAF); a construção da Rede de Técnicos e Investigadores sobre Tecnologias para a Agricultura Familiar (RedTAF); a criação do Programa de Apoio a Pequenos e Médios Produtores (PAPyMP); e as mudanças no Programa de Desenvolvimento de Pequenos Produtores Agropecuários (PROINDER) (JUÁREZ et al., 2014; LATTTUADA; NOGUEIRA; URCOLA, 2015).

Por sua vez, no Uruguai a construção de políticas para a agricultura familiar também é relativamente recente. Álvarez et al. (2014) destacam que esta agenda tem sido influenciada pelos países vizinhos a partir da REAF e com a incorporação de um eixo de investigação sobre a agricultura familiar no Programa Cooperativo para o Desenvolvimento Tecnológico Agroalimentar e Agroindustrial do Cone Sul (PROCISUR). Segundo os autores, a partir de 2005 foi estabelecido um conjunto de ações voltadas para o segmento, destacando-se: a criação da Direção Geral de Desenvolvimento Rural (DGDR) no Ministério da Pecuária, Agricultura e Pesca (MGAP); as mudanças na regulação do mercado e na política de terras por meio da atuação do Instituto Nacional de Colonização (INC); o processo de Registro de Produtores Familiares; a incorporação de uma linha de trabalho sobre agricultura familiar pelo Instituto Nacional de Investigação Agropecuária (INIA); a criação das Mesas de Desenvolvimento Rural como fóruns participativos territorializados; o debate e a institucionalização de mecanismos de compras públicas da agricultura familiar, e as ações de crédito rural, seguro agrícola e política de assistência técnica e extensão rural.

Um marco importante no Paraguai foi a institucionalização da Lei n. 1.863/2001, a qual estabeleceu o Estatuto Agrário, reconhecendo a importância de incorporar a agricultura familiar no desenvolvimento nacional. Três anos depois, a Lei nº 2.419/2004 criou o Instituto Nacional de Desenvolvimento Rural e da Terra (INDERT) e institucionalizou uma definição de "agricultura familiar campesina". Além do reconhecimento político e normativo, o governo paraguaio também desenvolveu outras ações e políticas ao longo dos últimos anos, como o Programa de Fomento à Produção de Alimentos da Agricultura Familiar (PPA); o Programa Nacional de Apoio à Agricultura Familiar (PRONAF); o Programa Agricultura e Economia Indígena (PAEI); o Programa de Fomento e Promoção da Equidade de Gênero e Juventude Rural; o Projeto Paraguai Rural - que focaliza a inserção da agricultura familiar em cadeias de valor -, e a criação de mecanismos de mercados institucionais para esta categoria social (FIDA, 2013). 
Esses instrumentos elucidam as repercussões que os diálogos regionais desencadearam para a construção e harmonização de um arranjo institucional para a agricultura familiar no Mercosul ${ }^{2}$. Obviamente, a REAF não é o único fórum que organiza e promove este diálogo. Há outros espaços com maior ou menor nível de formalização, abertura à participação social e capacidade de formulação. Mas a REAF cumpre um papel importante para ampliar a escala deste processo; para legitimar as lutas por reconhecimento travadas no interior dos países, dos governos e das organizações sociais; para promover novas formas de aprendizagem institucional por meio do compartilhamento de conhecimentos e experiências; e para fortalecer os processos democráticos, inclusive mediando conflitos políticos que, internamente, podem bloquear o funcionamento dos espaços nacionais de concertação social (MIELITZ NETO, 2011).

Mesmo naqueles países onde a criação de políticas e institucionalidades foi freada pela resistência imposta por setores conservadores, geralmente vinculados aos "agronegócios" (PIÑERO; CARDELLAIC, 2014), a REAF conseguiu ao menos cumprir um papel central para legitimar as lutas sociais pelo reconhecimento das agriculturas familiares, camponesas e indígenas. Ao longo do tempo, diferentes movimentos sociais (e também organizações multilaterais como o FIDA e a $\mathrm{FAO}^{3}$ ) passaram a apoiar e a utilizar este fórum e as propostas ali construídas como um elemento de reforço discursivo em suas lutas políticas/institucionais para justificar o apoio ou a oposição a determinadas políticas e regulamentações (RIELLA, 2002). Trata-se de uma espécie de "efeito boomerang" (KECK; SIKKING, 1998) do processo de disseminação internacional de políticas públicas, por meio do qual as demandas, reivindicações e denúncias de determinados atores são remetidas para esta instância regional com a intenção de retornar e retroalimentar o debate interno dos movimentos e organizações.

2 A Venezuela foi incorporada ao bloco em 2012, o que explica um menor nível de institucionalização da agricultura familiar, repercutindo igualmente em instrumentos de políticas públicas que seguem conceitos distintos. No caso dos países, associados, a situação é bastante heterogênea. Alguns exemplos serão discutidos infra.

3 O Programa Fida Mercosul foi essencial ao longo de todo o processo de constituição da REAF, seja do ponto de vista do aporte de recursos financeiros, seja no que diz respeito à assessoria permanente para a formatação da estrutura organizacional e dos princípios metodológicos. Ao mesmo tempo, a experiência da REAF fomentou a reorganização do Programa. No caso da FAO, embora o processo de aproximação seja mais recente, hoje ela é a entidade que gestiona administrativamente os recursos do Fundo da Agricultura Familiar (FAF). Ademais, há um crescente entendimento entre a agenda da FAO e da REAF, haja vistas as discussões em torno de temas como o Ano Internacional da Agricultura Familiar (AIAF), comemorado pela ONU em 2014, e as Diretrizes Voluntárias para uma Gestão Responsável da posse da Terra, Pescas e Florestas (FAO, 2015).

Novos Cadernos NAEA • v. 20 n. 1 • p. 67-94 • jan-abr 2017 


\section{DA DEFINIÇÃO REGIONAL ÀS LEGISLAÇÕES NACIONAIS}

Diversidade é a palavra-chave para acessar o conteúdo da agricultura familiar latinoamericana (CRAVIOTTI, 2012; SCHNEIDER; CASSOL, 2014). Assim, todos os esforços de definição desta categoria sociopolítica se deparam com o desafio de abarcar uma pluralidade formas de produção lastreadas por relações socioculturais que guardam inúmeras especificidades históricas e espaciais (PIÑERO, 2005; NEVES, 2002). Desde suas primeiras reuniões, a REAF tem sido desafiada a manejar esta diversidade. A expressão mais evidente disto é o modo como os movimentos campesinos e indígenas demandam o reconhecimento de suas identidades particulares no seio da configuração mais ampla que se formou em torno da agricultura familiar. Como destaca uma representante das nações e povos indígenas da Argentina, esta demanda envolve inclusive a criação de grupos específicos para tratar das suas demandas, o que, até o momento, não foi adotado em virtude, segundo membros da Secretaria Técnica da REAF, do risco de segmentação social e dos custos envolvidos para garantir o funcionamento dos GT.

La REAF es un espacio de profundo crecimiento para las organizaciones. Es un espacio que nos ha servido para fortalecernos como organización. Es un espacio que ha sido muy útil y un instrumento importante para conocer a otras organizaciones de la región, intercambiar experiencias, intercambiar realidades, entender que, como región, teníamos puntos e ejes comunes. Y también el espacio de la REAF nos a permitido un crecimiento como sujetos políticos, como sujetos de derechos que somos. [...] El avance en la participación de las organizaciones de la agricultura familiar, incluyendo cada vez más también a los pueblos indígenas. Los compañeros están solicitando que se cree en este espacio también un grupo temático de pueblos indígenas, ya que también tenemos nuestras particularidades y, por consiguiente, son necesarias políticas particulares para nuestro sector, así como ha sido necesario en el GT de mujeres y de juventud. Esta propuesta ha sido conversada desde el año 2009, pero concretamente surgió más en el año pasado, y este año ya está siendo impulsada por las organizaciones de varios países (Representante de povos originários no PARLASUL. Estrato de entrevista concedida em junho de 2015).

Para assegurar uma unidade conceitual, os gestores públicos e as lideranças sindicais que mais precocemente adotaram a agricultura familiar em seus discursos - tais como a Confederação Nacional dos Trabalhadores na Agricultura (CONTAG, Brasil), a Federação Agrária Argentina (FAA) e a Comissão Nacional de Fomento Rural (CNFR, Uruguai), além da Coordenadora 
de Organizações de Produtores Familiares do Mercosul (COPROFAM) - sempre fizeram questão de sustentar que existe um "air de famille" entre o camponês paraguaio e o indígena do altiplano boliviano; entre o pequeno pecuarista do chaco argentino e o assentado do semi-árido brasileiro. Apesar das diferenças, eles portariam características que permitem lhes atribuir uma identidade comum. Uma identidade sociopolítica construída de maneira relacional e em oposição aos segmentos do agronegócio/patronato que historicamente dominaram os espaços de produção de políticas públicas nos países sulamericanos.

A agricultura familiar é o resultado de um processo político construído na intersecção entre a ação reivindicatória dos movimentos sociais, a renovação dos estudos rurais e o protagonismo do Estado na criação de novas políticas de desenvolvimento rural (NIEDERLE; FIALHO; CONTERATO, 2014). Portanto, é compreensível que em cada país este processo tenha assumido temporalidades e características específicas. Ao mesmo tempo, é factível que este processo tenha sido objeto de inúmeras controvérsias, inclusive por parte dos movimentos sociais. No espaço regional, quando da criação da REAF, alguns movimentos mantiveram-se alheios ao processo, às vezes questionando os rumos das discussões e dos acordos estabelecidos. Este é o caso da Via Campesina, que, inicialmente, preferiu ratificar uma identidade "campesina" como alicerce de suas lutas políticas, questionando a coalizão mais híbrida e contraditória que se formava em torno da noção de agricultura familiar. Embora movimentos locais e nacionais vinculados à Via Campesina já participassem desde as primeiras reuniões da REAF, foi apenas em 2015 que ela passou a participar como movimento-rede internacional.

Mas a agricultura familiar somente conseguiu se impor como uma noção guarda-chuva para unificar os discursos e os interesses políticos no contexto regional à medida que governos e movimentos sociais compreenderam que ela não poderia substituir outras identidades mais específicas. Pelo contrário, deveria fortalecê-las. E para isso era necessário conferir visibilidade e voz para uma miríade de grupos e populações rurais. É por isso que, junto com a agricultura familiar, no período mais recente a REAF passou a incorporar as noções "campesina" e "indígena" aos seus documentos. Isto se revelou fundamental para formar uma coalizão mais ampla, fazendo com que o fortalecimento da agricultura familiar resultasse, ao mesmo tempo, no reconhecimento de outras identidades e na ampliação do fórum.

Mas esta ampliação repercute na readequação do arranjo normativo e no acesso aos instrumentos de políticas públicas? Não cabe ao escopo deste texto analisar as assimetrias no acesso às políticas públicas. Mas é fundamental aqui discutir como esta heterogeneidade tem sido incorporada nos instrumentos 
legais de definição e identificação da agricultura familiar. O Quadro 1 sintetiza as denominações e os critérios de delimitação da categoria utilizados em cada país. ${ }^{4}$ As diferenças iniciam pela própria denominação adotada em cada país: Agricultor familiar (Brasil e Argentina), Agricultor Familiar Campesino (Paraguai) e Produtor Familiar (Uruguai). Note-se que, enquanto a definição paraguaia acentua o caráter campesino da população rural, a noção uruguaia de "produtor familiar" reconhece que a maioria dos estabelecimentos rurais dedicase fundamentalmente à pecuária, característica singular da história agrária deste país. Como destaca o Ponto Focal uruguaio no Grupo Técnico de Registros da REAF, gestor público na Direção Nacional de Desenvolvimento Rural,

Nosotros hablamos de Productores Familiares y no de agricultores familiares. Porque hablamos de Productores Familiares? Respetamos el hecho de que la mayoría de nuestros agricultores familiares son ganaderos. Este es el resultado del diálogo que se generó con todos los actores que trabajaban en el Ministerio de Agricultura y también en la sociedad civil, en la Sección Nacional (da REAF). Además, fue realizada una consulta nacional para las organizaciones sociales (Gestor na Direção Nacional de Desenvolvimento Rural, Uruguai. Entrevista concedida em março de 2015).

A unidade conceitual recai sobre a natureza familiar do trabalho e da gestão. Outrora identificada por outro tipo de adjetivação, mais diretamente associada a variáveis econômico-produtivas (pequenos produtores, minifundiários, produtores de subsistência, população rural de baixa renda), a noção de agricultura familiar institucionaliza um novo olhar sobre este grupo social, o qual já não focaliza prioritariamente os limites de propriedade, a incompletude das relações mercantis ou a incapacidade de aferir renda monetária, ainda que critérios deste tipo continuem recorrentes para definir o acesso às políticas públicas (vide próxima seção). Em todos os países, é a predominância do trabalho e da gestão familiar que constituem o principal esteio desta definição. Mesmo assim, há diferenças normativas no que diz respeito aos limites para incorporação de mão de obra externa ao estabelecimento, bem como à possibilidade de individualização do processo de gestão.

4 Para evitar uma confusão recorrente entre as definições normativas apresentadas nesta seção e os Registros Nacionais da Agricultura Familiar, desde já é importante destacar que estes podem se basear em normas mais específicas, visando a identificação do público beneficiário das políticas públicas. Estas serão abordadas na próxima seção. À título de ilustração, enquanto, no Brasil, a Lei 11.326/2006 exige apenas a necessidade um percentual mínimo da renda ser proveniente do estabelecimento familiar, a Declaração de Aptidão ao PRONAF (DAP) estabelece que, no mínimo, $50 \%$ da renda bruta deve ser originada da exploração agropecuária e não agropecuária do estabelecimento, bem como um limite máximo de $\mathrm{R} \$ 360$ mil de renda bruta anual familiar. 
Do mesmo modo, a extensão geográfica da propriedade sempre constituiu um parâmetro-chave para diferenciar estes grupos sociais no universo dos estabelecimentos agropecuários. Isto é decorrência da própria origem das discussões políticas sobre a agricultura familiar, a qual esteve associada às reivindicações dos pequenos agricultores minifundistas e dos movimentos de luta pela terra. Este critério permanece nas legislações brasileira e uruguaia, mas nada consta a respeito neste nível normativo nos casos argentino e paraguaio.

O parâmetro rendimento também é recorrente nas discussões conceituais. Inicialmente, havia uma preocupação tanto dos gestores públicos quanto das próprias organizações da sociedade civil para que as políticas diferenciadas não fossem apropriadas por atores com maior poder econômico. Os exemplos históricos das políticas de modernização dos anos 1960-1970, sobretudo da concentração do crédito, ratificavam este tipo de inquietação. Assim, alguns países passaram a estabelecer limites de renda por estabelecimento. Hoje, as legislações relativas à definição da agricultura familiar não abarcam estes limites, mas, como veremos à frente, eles são utilizados como critério para acesso às políticas públicas, incorporados nos Registros Nacionais.

No que tange ao universo das leis e resoluções nacionais, a principal preocupação dos gestores no momento de institucionalização da categoria esteve associada com a garantia de que os rendimentos fossem predominantemente provenientes do estabelecimento - o que se torna ainda mais estrito na Argentina, que estipula a prevalência de rendas com origem nas atividades agropecuárias. Este tipo de regra tem produzido importantes discussões no período recente, sobretudo em virtude dos constrangimentos que cria ao desenvolvimento da pluriatividade e da multifuncionalidade da agricultura familiar.

Finalmente, há um parâmetro relacionado ao local de residência, o qual é relevante àquelas regiões que presenciaram a migração para os centros urbanos de agricultores que, sem residir no estabelecimento rural, mantiveram a posse e o uso da terra para fins agropecuários e em regime de economia familiar. Embora não esteja presente em todas as legislações citadas no Quadro 1, os países procuram estabelecer um perímetro dentro do qual o(a) agricultor(a) e sua família devem residir - o que, teoricamente, atestaria a possibilidade dos mesmos continuarem desempenhando normalmente a gestão e o trabalho na unidade familiar de produção. 


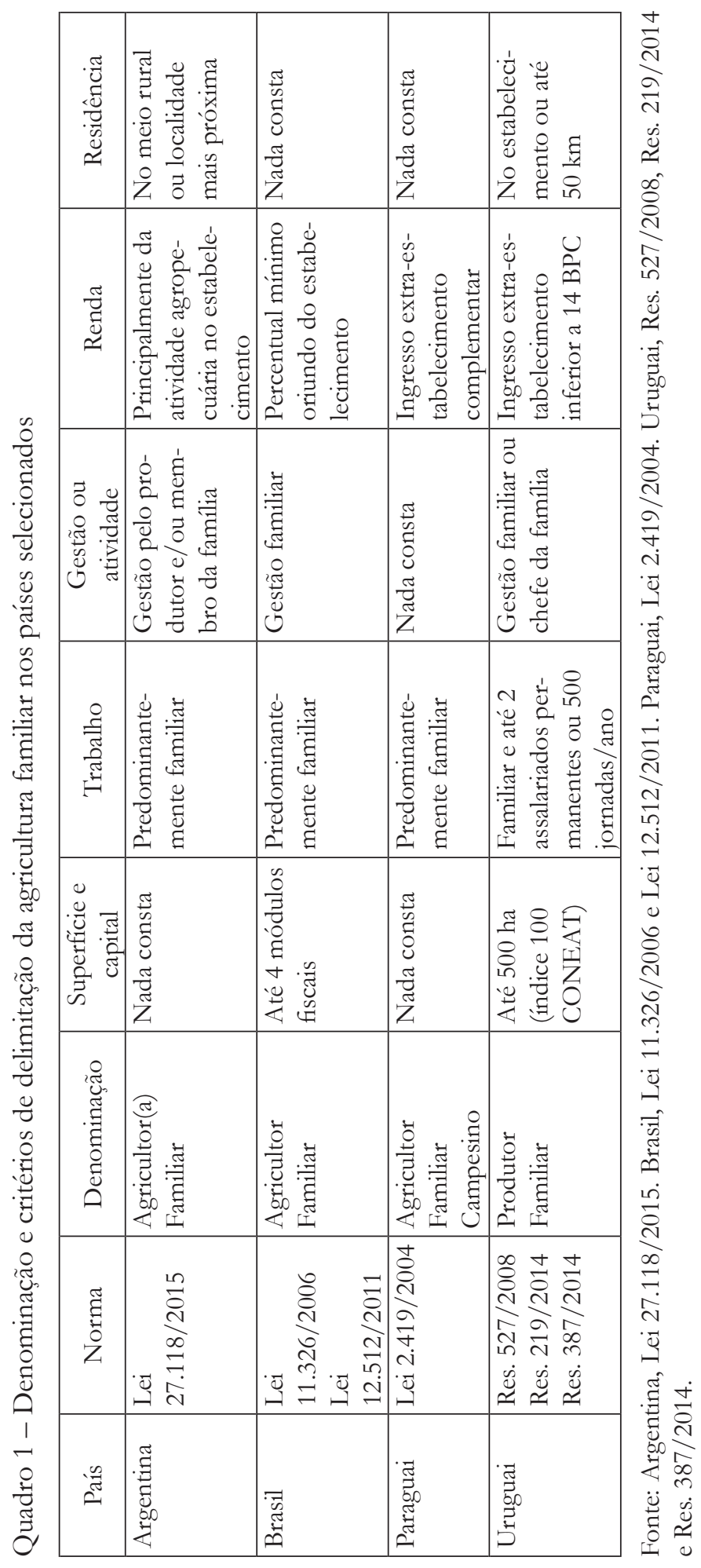

Novos Cadernos NAEA • v. 20 n. 1 • p. 67-94 • jan-abr 2017 
Dentre todas as legislações, o caso mais destoante é o do Paraguai, cuja regra acentua o caráter campesino e minifundista de grande parte da sua agricultura familiar. O país define a agricultura familiar como aquela que possui "produção basicamente de autoconsumo e parcialmente mercantil, completando os ingressos a partir de outras produções de caráter artesanal ou extra estabelecimento.” (Lei $\mathrm{n}^{\circ}$ 2.419/2004). Esta definição ratifica uma leitura outrora bastante recorrente nos estudos rurais sobre a situação de "integração parcial" dos camponeses a “mercados incompletos" (ELLIS, 1988). Ou seja, uma perspectiva que define o campesinato a partir de sua condição de reproduzir parte dos meios de produção sem acessar os mercados e, fundamentalmente, à flexibilidade entre consumo e venda, que permite, estratégica e temporariamente, se retirar dos mercados sem comprometer a reprodução social.

A legislação paraguaia também não abarca parâmetros de superfície e capital, gestão familiar ou local de residência. No entanto, é imprescindível considerar que, neste caso, estamos tratando da Lei no 2.419/2004, a qual criou o Instituto Nacional de Desenvolvimento Rural e da Terra. Como veremos à frente, posteriormente, o país também incorpora critérios mais específicos, mas isto já é fruto das discussões conduzidas no âmbito da Seção Nacional da REAF com vistas à implantação do Registro Nacional.

Por sua vez, o caso uruguaio merece outro destaque para além da diferença nominativa (Produtor Familiar). De modo geral, pode-se dizer que a regulamentação do país incorpora critérios mais estritos comparativamente aos demais. Teoricamente, um nível muito alto de especificações impõe dificuldades para futuras demandas por readequações dos critérios de enquadramento, haja vista, sobretudo, a necessidade de renegociações políticas entre os poderes executivo e legislativo. No caso uruguaio, contudo, a situação é menos complicada na medida em que a normatização em vigor decorre de Resoluções internas do Ministério de Pecuária, Agricultura e Pesca (MGAP). De outro modo, na Argentina e no Brasil, onde foram aprovadas leis que necessitam tramitar nos Congressos Nacionais, existem parâmetros mais gerais de definição, o que confere maior margem de manobra para os gestores operarem.

O Chile trabalha com critérios muito próximos àqueles apresentados acima, exceto pela centralidade do acesso à água. Membro associado ao Mercosul e participante ativo da REAF deste os primeiros anos, o país possui um longo percurso no que diz respeito à discussão sobre a agricultura familiar. Atualmente, seguindo a Lei n⿳o 18.910/1990, o Instituto de Desenvolvimento Agropecuário (INDAP) reconhece dentre os "agricultores familiares campesinos" dois públicos:

(a) Pequeno produtor agrícola: pessoa que trabalha a terra em uma superfície

Novos Cadernos NAEA •v. 20 n. $1 \bullet$ p. 67-94 • jan-abr 2017 
não superior a 12 ha de "irrigação básica", cujos ativos não superem 3.500 Unidades de Fomento, e que seu ingresso seja principalmente proveniente do estabelecimento agrícola; (b) Campesino: pessoa cujas atividades sejam oriundas fundamentalmente da atividade silvoagropecuária sempre que suas condições econômicas não sejam superiores àquelas de um pequeno produtor agrícola.

Recém ingressante no Mercosul, a Venezuela possui um conceito de "agricultura familiar comunal" que se estrutura a partir da família ampliada de caráter matriarcal, a qual predomina nas comunidades campesinas e indígenas. Trata-se de um modelo de economia comunitária que traz para os diálogos da REAF uma nova realidade. Juntamente com Bolívia e Equador, países associados ao Mercosul, as particularidades do caso venezuelano podem impulsionar uma nova rodada de discussões em torno da definição conceitual da agricultura familiar, quiçá fortalecendo o reconhecimento de segmentos sociais que não se enquadram facilmente nos parâmetros acima referidos, como os povos originários e as comunidades tradicionais. Estes geralmente possuem modos de produção e propriedade diferenciados, envolvendo a posse e a gestão comunal de recursos naturais situados em territórios extensos.

Algumas legislações nacionais já buscaram abarcar outros grupos sociais que não se enquadram nos parâmetros acima. Na Argentina, por exemplo, a Lei 27.118/2015 de "Reparação Histórica da Agricultura Familiar para a Construção de uma Nova Ruralidade" também enquadra como agricultores familiares os pequenos produtores, minifundiários, campesinos, chacareros, colonos, meeiros, pescadores artesanais, produtores familiares, produtores sem terra, produtores periurbanos e as comunidades de povos originários. No Brasil, a Lei 11.326/2006, complementada pela Lei 12.512/2011, mesmo não os equiparando diretamente ao conceito de agricultor familiar, estabelece que também são beneficiários da Política Nacional da Agricultura Familiar: (a) silvicultores que cultivem florestas nativas ou exóticas e que promovam o manejo sustentável daqueles ambientes; (b) aqüicultores que explorem reservatórios hídricos com superfície total de até dois hectares ou ocupem até $500 \mathrm{~m}^{3}$ de água; (c) extrativistas que exerçam atividade artesanalmente no meio rural, excluídos os garimpeiros e faiscadores; (d) pescadores artesanais; (e) povos indígenas; e (f) integrantes de comunidades remanescentes de quilombos rurais e demais povos e comunidades tradicionais.

Com uma lógica similar àquela do "módulo rural" no Brasil, "riego básico" corresponde a uma superfície equivalente à potencialidade de produção de uma área física padrão estipulada a partir do Vale do Rio Maipo (ver Lei 18.910 de 1990). 


\section{OS SISTEMAS NACIONAIS DE REGISTRO VOLUNTÁRIO DOS AGRICULTORES FAMILIARES}

Os Registros Nacionais são instrumentos criados pelos governos para identificar os agricultores familiares que podem ser beneficiários de políticas diferenciadas, às vezes garantindo exclusividade. Os registros também permitem construir bases de dados sobre esta categoria social e, assim, contribuem para aperfeiçoar as políticas públicas. A última atualização publicada pela REAF em dezembro de 2015 dava conta de 5,3 milhões de unidades registradas entre Argentina, Brasil, Paraguai e Uruguai (ainda não há registros nos demais países).

Em virtude de ter seu sistema institucionalizado há mais tempo, o Brasil apresenta o maior percentual relativo de agricultores registrados, o qual inclusive supera o número de estabelecimentos recenseados pelo último Censo Agropecuário (Tabela 1). Atualmente, o registro brasileiro abarca 115\% dos estabelecimentos recenseados, o que é possível na medida em que um mesmo estabelecimento pode conter mais de uma unidade familiar de produção. Este tipo de diferença também se expressa nos demais países, como no caso uruguaio onde o registro contabiliza produtores com área inferior a 1 ha, excluídos pelo recenseamento.

Tabela 1 - Unidades familiares e agricultores/as familiares registrados até 2015.

\begin{tabular}{|l|r|r|r|r|r|r|}
\hline País & $\begin{array}{c}\text { Unidades } \\
\text { familiares } \\
\text { registradas }\end{array}$ & $\begin{array}{c}\text { Estabelecimen- } \\
\text { tos familiares } \\
\text { (Censos } \\
\text { agropecuários) }\end{array}$ & $\begin{array}{c}\text { \% estab. } \\
\text { registrados } \\
\text { / Estab. } \\
\text { Total }\end{array}$ & $\begin{array}{c}\text { Agricultores } \\
\text { familiares } \\
\text { registrados }\end{array}$ & Homens & Mulheres \\
\hline Argentina & 109.189 & 251.116 & 43,5 & 384.030 & 199.562 & 184.378 \\
\hline Brasil & 5.045 .122 & 4.367 .902 & 115,5 & 9.694 .4455 & 5.566 .527 & 4.127 .928 \\
\hline Paraguai & 177.686 & 264.821 & 67,1 & 710.744 & 374.976 & 335.768 \\
\hline Uruguai & 23.446 & 25.285 & 92,7 & 31.408 & 19.149 & 12.259 \\
\hline Total & 5.355 .443 & 5.169 .124 & 103,6 & 10.820 .637 & 6.160 .304 & 4.660 .333 \\
\hline
\end{tabular}

Fonte: REAF. Informe sobre os Registros Nacionais da Agricultura Familiar no Mercosul. Dezembro de 2015.

O aprendizado derivado da experiência brasileira foi fundamental para balizar os debates regionais. O próprio MDA salienta que a Declaração de Aptidão ao Pronaf (DAP), instrumento de registro existente no Brasil, é "referência internacional entre os países do Mercosul." (Brasil, MDA, 2014, p. 13). De fato, os termos definidos na Resolução GMC no 25/2007 se aproximam daqueles previamente encontrados na DAP e na Lei da Agricultura Familiar, as quais foram estabelecidas, respectivamente, em 1997 e 2006. Mas a norma 
brasileira não foi replicada mecanicamente. Carvalho (2011, p. 50) salienta que "a definição [estabelecida na REAF] abre espaço para contemplar diferenças nacionais, tais como a extensão das propriedades na Amazônia brasileira ou na Patagônia argentina, mantendo também a capacidade de decisão dos países sobre sua definição própria de agricultura familiar.” Uma das inovações regionais está na "identificação tanto dos homens como das mulheres da agricultura familiar, independentemente de seu estado civil." Até então, no Brasil, o foco recaía quase exclusivamente nos estabelecimentos agropecuários. Ademais, o Mercosul adotou um critério referente aos recursos produtivos e à tecnologia adotada, o que não é abordado na definição brasileira e, até o momento, não tem se traduzido efetivamente em variáveis de factíveis de aferição.

Estabelecida em 1997 (mas tendo sua emissão controlada somente a partir de 2001) ${ }^{6}$, a DAP foi o mecanismo utilizado pelo governo brasileiro para garantir acesso exclusivo dos agricultores familiares ao PRONAF, sendo esta a primeira política nacional direcionada especificadamente para o segmento, criada em 1995. Atualmente, este instrumento serve de parâmetro para o acesso a todas as políticas públicas que se destinam a este segmento social, sejam elas geridas pelo Ministério do Desenvolvimento Agrário (principalmente) ou por outros ministérios e autarquias públicas. Após diversas modificações, mas coerente com a definição assumida inicialmente para a operacionalização do PRONAF, a DAP assegura condições mais restritivas que a Lei da Agricultura Familiar (11.326/2006), sobretudo no que diz respeito aos limites de rendimento dos estabelecimentos. Atualmente, deve-se atender aos seguintes critérios:

a) explorar parcela de terra na condição de proprietário, posseiro, arrendatário, comodatário, parceiro, concessionário do Programa Nacional de Reforma Agrária, ou permissionário de áreas públicas;

b) residir no estabelecimento ou em local próximo, considerando as características geográficas regionais;

c) não deter área superior a quatro módulos fiscais;

d) deter, no mínimo, $50 \%$ da renda bruta originária da exploração agropecuária e não agropecuária do estabelecimento;

e) ter o trabalho familiar como predominante na exploração do estabelecimento, utilizando mão de obra de terceiros de acordo com as exigências sazonais da atividade agropecuária, podendo manter empregados permanentes em número menor que o número de pessoas da família ocupadas com o empreendimento familiar;

f) ter obtido renda bruta familiar nos últimos doze meses de até $\mathrm{R} \$ 360$ mil reais.

Até junho de 2001 não havia controle sobre os registros da agricultura familiar. Bastava uma simples autodeclaração, jurada por um dos membros da unidades familiar, em conjunto com um técnico ou representante das formas associativas dos agricultores familiares. 
Inicialmente, a emissão da DAP era quase exclusividade dos Sindicatos de Trabalhadores Rurais e dos órgãos de Assistência Ténica e Extensão Rural. Embora estes atores continuem capitaneando o processo, hoje existe uma gama maior de organizações aptas cadastradas junto à Secretaria da Agricultura Familiar (SAF/MDA), o que se deve, basicamente, à necessidade de alcançar segmentos não contemplados pelas organizações sindicais e, às vezes, pela própria ação dos extensionistas: Instituto Nacional de Colonização e Reforma Agrária (INCRA) para os assentados de reforma agrária; Fundação Nacional do Índio (FUNAI) para os povos originários; Instituto Chico Mendes de Conservação da Biodiversidade (ICMBio) para comunidades extrativistas; e Fundação Cultural Palmares para as comunidades remanescentes de quilombos. Atualmente, 26.787 agentes cadastrados realizam a emissão das DAP (BRASIL, 2014).

Em termos operacionais, nos casos em que os agricultores podem se deslocar até as organizações de registro, as mesmas aplicam um questionário eletrônico que é encaminhado diretamente para validação junto ao MDA. Nos demais casos, há uma ação mais proativa dos técnicos, incluindo mutirões de documentação para alcançar agricultores em comunidades mais isoladas. Ademais, para além do controle e da validação de informações que ocorre pelos próprios agentes públicos e organizações sociais implicadas, as DAP devem ser objeto de controle social nos Conselhos Municipais de Desenvolvimento Rural Sustentável (CMDRS), os quais podem solicitar o cancelamento do registro em casos de irregularidades cadastrais.

Associado ao registro dos estabelecimentos, o Brasil também criou um instrumento de identificação das organizações da agricultura familiar denominado DAP Jurídica. Este instrumento é utilizado para "identificar e qualificar as formas associativas das unidades familiares de produção rural organizadas em pessoas jurídicas" (BRASIL, 2014, p. 14). Para tanto, exigiase que a pessoa jurídica fosse formada apenas por agricultores familiares. No entanto, rompendo com concepções que presumiam a endogenia ou isolamento social dos mesmos, as regras foram flexibilizadas. O percentual inicialmente caiu para 90\% e, posteriormente, foi reduzido até alcançar, atualmente, a proporção de 60\% como limite mínimo de participação de agricultores familiares com DAP física. Hoje existem 5.014 organizações registradas, sendo 65\% associações, $29 \%$ cooperativas e $6 \%$ de outros tipos (REAF, 2015).

$\mathrm{Na}$ Argentina a discussão sobre os registros também é anterior à Resolução do bloco, ainda que diretamente influenciada pelas discussões que já estavam em curso na REAF. Com a criação do Fórum Nacional da Agricultura Familiar (FoNAF), em 2006 começou-se a delinear um Registro Nacional, "considerado 
um instrumento básico para a execução das políticas públicas dirigidas ao setor" (REAF, 2013, p. 08). Em 2007, no bojo dos debates para redação da Resolução GMC no 25, a então Secretaria de Agricultura, Pecuária, Pesca e Alimentos (SAGPyA) publicou a Resolução n. 255 que torna o Registro Nacional da Agricultura Familiar (RENAF) "o único meio pelo qual os agricultores familiares poderão acessar aos benefícios dos instrumentos de políticas públicas diferenciadas para o setor”. Mais recentemente, a Lei no 27.118/2015 estabeleceu a obrigação dos Agricultores e Agricultoras Familiares registrarem-se de forma individual e associativa para ser incluídos como beneficiários das políticas, destacadamente, do Monotributo Social Agropecuário e do Plano de Inclusão à Aposentadoria.

A coordenação do processo está a cargo da Unidade de Registro Nacional da Agricultura Familiar (URAF). Por sua vez, o registro incide sobre o Nucleo Agricultor Familiar (NAF), sendo este a pessoa ou o grupo de pessoas, parentes ou não, que habitam sob um mesmo teto em um regime de tipo familiar, isto é, compartilham seus gastos em alimentação ou outros bens essenciais para viver e que aportem ou não força de trabalho para o desenvolvimento de alguma atividade no âmbito rural. Para o caso de população indígena, o conceito equivale ao de comunidade. Ademais, são considerados NAF todas as famílias ou estabelecimentos de produtores/as agropecuários/as, florestais, pescadores/ as, coletores/as e/ou com atividades artesanais, agroindustriais ou turísticas, que utilizem recursos de origem agrária, sem importar se o destino destas atividades é a venda, o autoconsumo ou a troca, ou se é a atividade principal ou secundária, considerando a adequação aos seguintes critérios:

a) vivem em áreas rurais ou a uma distância que permita contatos frequentes com a produção agrária ou conexas;

b) a mão de obra ocupada corresponde predominantemente à família e é limitada a contratação de mão de obra;

c) a renda de fora do estabelecimento é limitada a um máximo de três salários mínimos de peão rural por mês;

d) assumam a responsabilidade/controle sobre sua atividade produtiva. (REAF, 2014)

O preenchimento dos formulários de registro é feito por registradores habilitados vinculados às organizações de agricultores familiares, além de técnicos de campo da Secretaria de Agricultura Familiar do MGAyP. Os dados são averiguados e controlados em várias instâncias do processo de Registro, desde a escala local e provincial até a central. Atendidos todos os critérios e as etapas de verificação, a listagem dos agricultores familiares é publicada em um sítio da 
internet, tornando-se sujeita ao controle social, mas este não envolve conselhos públicos como no caso brasileiro.

A Argentina também implementou um instrumento específico para as organizações da agricultura familiar. O Registro Nacional de Organizações da Agricultura Familiar (RENOAF) é voluntário e não abarca critérios de formalização jurídica tal qual ocorre no Brasil. Os requisitos mínimos de registro exigem que a organização detenha ao menos dez integrantes e que, no mínimo, 70\% dos sócios ou cooperados devem cumprir os requisitos de agricultor familiar (enquadramento ao RENAF). Até 2015 foram registradas 409 organizações e outras 334 estão em processo de registro. Estimativas do governo argentino sugerem que existem outras 3147 organizações para serem registras (REAF, 2015).

Por sua vez, o Paraguai foi, de acordo com Carvalho (2011, p. 120), “o primeiro país a, depois da Resolução GMC n 25/07, começar a implementar o registro de agricultores familiares, ainda em 2007, como o nome de Registro Nacional da Agricultura Familiar (RENAF)". No entanto, ainda segundo a autora, o "registro foi realizado na mesma época de uma entrega de subsídios para perdas por fenômenos climáticos [Certificado Agrícola], criando confusão entre a população, que associou o preenchimento dos dados para o registro ao recebimento dos subsídios". Em virtude disto e de outros fatores institucionais, "apenas em 2010 o governo paraguaio finalmente reordenou o formulário, que tinha problemas, e previa recomeçar a coleta de dados" (CARVALHO, 2011, p. 116).

Seguindo parâmetros mais estritos que aqueles estabelecidos pela Lei n. 2.419/2004 (supra), o registro paraguaio considera agricultura familiar a atividade produtiva rural que se executa utilizando principalmente a força de trabalho familiar para a produção de um estabelecimento e, que, que, além disso:

a) não contrata no ano um número maior do que 20 diaristas assalariados de maneira temporária em épocas específicas do processo produtivo;

b) reside na propriedade e/ou em comunidades próximas;

c) não utiliza, sob qualquer condição, seja na propriedade, arrendamento, ou outra relação, mais que 50 hectares na Região Oriental e 500 hectares na Região Ocidental de terras independentemente da cadeia produtiva (REAF, 2015).

Sob responsabilidade do Departamento de Registro da Agricultura Familiar na Direção de Censos e Estatísticas Agropecuárias (DCEA), o RENAF constitui um instrumento técnico e de política pública que identifica e caracteriza uma unidade produtiva da agricultura familiar, sendo esta condição fundamental 
para acessar os serviços públicos. ${ }^{7}$ No Paraguai, dentre as políticas que utilizam o RENAF como parâmetro de identificação do seu público estão o Programa de Fomento da Produção de Alimentos, as ações de Assistência Técnica, o Programa de Agricultura e Economia Indígena e o Programa Nacional de Fomento Pecuário. Até o momento o país não conta com um registro para as organizações coletivas.

No Uruguai, em 2006 teve início um primeiro esforço de delimitação conceitual da agricultura familiar com fins de intervenção do Estado. Impulsionados pelos debates da REAF, e também pelos diálogos para a reestruturação das políticas de desenvolvimento rural que o país vivenciava neste momento, este esforço culminou na elaboração da Resolução n. 527/2008 do MGAP, a qual apresenta uma primeira definição de "produtores familiares": (a) no máximo dois assalariados permanentes ou seu equivalente safral (até 500 jornadas anuais); (b) até 500 ha (Índice CONEAT 100), em qualquer forma de propriedade; (c) o ingresso do estabelecimento é o principal, ou cumpre sua jornada de trabalho no estabelecimento (d) reside no estabelecimento ou a, no máximo, $50 \mathrm{~km}$ do mesmo. Com vistas a alterar principalmente os critérios de rendimento, esta definição foi atualizada pelas Resoluções Ministeriais n. 219 e n. 387 de 2014, as quais estabelecem que "produtores/as familiares são pessoas físicas que, com ou sem a ajuda de outras, administram diretamente uma exploração agropecuária e/ou realizam uma atividade produtiva agrária que não requer o uso direto da terra." Esta pessoa, em conjunto com sua família, deve cumprir, concomitantemente, os seguintes critérios:

a) realizar a exploração do estabelecimento com a colaboração de, no máximo, dois assalariados permanentes ou seu equivalente em jornadas safrais (500 ao ano);

b) explorar até 500 hectares (CONEAT 100);

c) residir na exploração ou em uma distância menor a $50 \mathrm{~km}$ da mesma;

d) deter renda familiar nominal extra-estabelecimento menor ou igual a 14 BPC mensais em media. ${ }^{8}$

\footnotetext{
Em novembro de 2014, por meio do Decreto 2.651, foi criado o Registro Nacional de Beneficiários, que tem como objetivo registrar todos os beneficiários dos serviços do MAG, sem diferenciar se tem perfil de agricultura familiar. O Decreto expressa que o RENAF permanecerá como parte do novo registro e que os requisitos de elegibilidade e os critérios de exclusão do RENAF não sofrerão variações.

8 Há exceções para os produtores que declaram como renda principal a olericultura, fruticultura e viticultura, que podem contratar um equivalente de até 1250 jornadas safrais anuais. Por sua vez, para os produtores que se declaram como apicultores, não é considerado o requisito de residência e terra, aplicando-se um máximo de 1000 colméias.
} 
Uma particularidade importante do caso uruguaio é que tanto a operacionalização do Registro Nacional quanto a execução do Censo Geral Agropecuário recaem sob a responsabilidade do MGAP, o qual tem se empenhado em fazer convergir os parâmetros de identificação e reconhecimento. De outro modo, nos demais países do bloco existem órgãos específicos para as atividades de recenseamento, os quais nem sempre estão dispostos a alterar seus mecanismos de coleta e processamento de informações. O resultado é um pequeno descompasso entre os parâmetros utilizados em cada caso (Registro e Censo).

No Uruguai, as atividades de Registro de Produtores Familiares iniciaram em 2009. Desde então, este se tornou a "ferramenta principal que tem a institucionalidade pública agropecuária uruguaia para a aplicação de políticas diferenciadas para a produção familiar a nível nacional" (SGANGA; CABRERA; GONZALEZ, 2013, p. 2). De acordo com um gestor público entrevistado, se inicialmente o registro foi impulsionado pela possibilidade de diferenciar um segmento particular para acessar benefícios de renúncia fiscal do Estado associados ao tema da seguridade social, atualmente este instrumento baliza um amplo conjunto de ações públicas, sobretudo da Direção Nacional de Desenvolvimento Rural, mas também de outros órgãos e institutos públicos: Projeto Uruguai Rural; Programa Pecuário; Planos de Negocio Granjeiros, Eletrificação Rural, Compras Públicas, Políticas de Seguridade Social.

Foi uma resolução ministerial que definiu a agricultura familiar, e depois houve uma lei que consolidou esta definição para uma política específica, que é a política que motivou basicamente o registro, que é um tema impositivo, um tema de seguridade social, é o BPS, Banco de Previdência Social, que são os aportes obrigatórios que realizam os produtores e que tem um benefício importante de renúncia fiscal. Foi isto que motivou internamente a criação e a implementação do registro, para além de todas as políticas diferenciadas que realiza a Direção Nacional de Desenvolvimento Rural, e outras políticas de outros institutos para as quais o registro é a base de aplicação. A definição é de agosto de 2008, a lei é de setembro, e o decreto regulamentar é de dezembro. E nós começamos a implementar o registro em março de 2009. Foi um ano de elaboração de todo o processo (Gestor do MGAP. Entrevista concedida em fevereiro de 2015).

O Registro uruguaio consiste em uma declaração jurada a partir de um formulário padronizado por produtor. Quem preenche o formulário é o produtor, mas para que ele se aproprie do processo é necessário contar com a colaboração das organizações sociais, que se encarregam de mobilizar os produtores, distribuir os formulários e auxiliar no preenchimento. Em seguida, inicia o processo de 
validação. A declaração é entregue a um funcionário do MGAP no território, que verifica os dados, avaliza o documento e encaminha para validação final pelos gestores nacionais. Os formulários são centralizados na Oficina de Registro de Produtores Familiares da DGDR/MGAP, onde se conferem, processam e sistematizam as informações. O próximo passo que está sendo discutido pelos gestores públicos é a possibilidade de validação social dos registros nas Mesas de Desenvolvimento Rural estabelecidas em âmbito territorial. Outra ação em curso é a construção do Registro Nacional de Organizações Habilitadas (RENAOH), criado em 2014 a partir da Lei 19.292 de compras públicas, a qual define uma organização da agricultura familiar como aquela que é integrada por pelo menos cinco pessoas e $70 \%$ dos integrantes sejam produtores familiares registrados.

Nos demais países do bloco, a implementação dos Registros encontrase em diferentes estágios. Como destaca um dos representantes do governo chileno na REAF, trata-se de uma discussão intrincada na medida em que pauta não apenas o acesso às políticas, mas também a construção da identidade sociopolítica dos grupos sociais. Segundo ele, o primeiro passo é a construção de um entendimento sobre a própria necessidade do registro, o que alguns atores compreendem como um questionamento inapropriado acerca da sua condição social. Por sua vez, outros tendem a conceber o registro como mais um empecilho burocrático no acesso aos recursos do Estado. Assim, somente após construir uma base sólida de entendimentos políticos consegue-se avançar para a institucionalização dos parâmetros de tipificação, algo que o Chile vem discutindo atualmente e que poderá desembocar na alteração da Lei Orgânica do INPAD, a qual, dentre outras providências, identifica o público beneficiário das políticas para a "agricultura familiar e campesina".

O primeiro passo que eu creio que foi fundamental é ter colocado na mesa de discussão a importância e a pertinência de ter um registro. Ou seja, isto já é um tremendo avanço. Quando começamos a conversar com as organizações e falamos 'vamos fazer um registro porque necessitamos saber quantos são, onde estão e quantos representam', as organizações se sentiram questionadas. [...] Mas, quando iniciamos a desenhar os instrumentos, quando iniciamos a ver os temas dos orçamentos, se deram conta de que os recursos são escassos e é necessário focalizar, é necessário priorizar, e a melhor forma é identificar os sujeitos da agricultura familiar (Gestor do INDAP, Chile. Entrevista concedida em dezembro de 2014).

Após estabelecidos os Registros Nacionais, o próximo passo da REAF foi a discussão do reconhecimento mútuo dos mesmos pelos países membros do bloco. Em 2012, o CMC publicou a Decisão no 59/2012 que, em seu artigo primeiro, "reconhece como agricultores familiares todas as pessoas inscritas nos 
Registros Nacionais da Agricultura Familiar segundo os critérios estabelecidos na

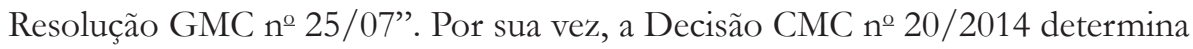
que os países devem desenvolver "procedimentos e rotinas que permitam o intercâmbio de dados e informações sobre seus respectivos Registros Nacionais da Agricultura Familiar, respeitando os procedimentos de segurança da informação adotados por cada Estado Parte" (Art. 2). A mesma Decisão também confere à REAF "responsabilidade de monitorar os dados e informação", com vistas a garantir a validade dos registros (Art. 3).

Em face destas determinações, o GT de Registros voltou sua atenção para a construção e utilização das bases de dados e informações, sobretudo às questões técnicas de operacionalização dos sistemas de informação, e às questões ético-normativas relacionadas à publicização dos dados - sobre o que as legislações nacionais versam de maneiras diferenciadas. Ademais, soma-se a isso a discussão sobre a atualização dos registros. O Uruguai, por exemplo, trabalha com formulários extensos e complexos, os quais buscam não apenas identificar, mas captar dados detalhados que ajudam a orientar os gestores no aperfeiçoamento das políticas - o que também determina maiores custos para efetuar atualizações. De outro modo, o Brasil possui um formulário simplificado, que abarca não mais do que as informações necessárias para enquadramento às regras da DAP. Isto faz com que os países trabalhem com bases de dados com níveis diferenciados de detalhamento, implicando em discussões acerca do que deve ser compartilhado por cada país.

\section{CONSIDERAÇÕES FINAIS}

Uma das chaves de leitura que podem ser mobilizadas para analisar o processo de institucionalização da agricultura familiar no Mercosul remete ao conceito de "policy transfer" (DOLOWITZ; MARSH, 2000). Cada vez mais recorrente nas ciências sociais e políticas, este conceito destaca os processos pelos quais o conhecimento sobre políticas públicas e arranjos institucionais presentes em um sistema político é utilizado para reinterpretar problemas e desenvolver soluções em outros contextos. Nesta perspectiva, pode-se arguir: teria o Brasil exportado um conceito de agricultura familiar - bem como os instrumentos de identificação e categorização desta categoria - para os demais países do bloco?

Quando enfrentados com este tipo de questionamento, a maioria dos entrevistados fez questão de rechaçar a ideia de transferência de política pública, pelo menos se ela pressupuser algum tipo de difusão unilateral. Segundo eles, e como corroboram os dados apresentados acima, a experiência brasileira reforçou 
uma "narrativa" (RADAELLI, 1998) acerca da importância da agricultura familiar e, por conseguinte, legitimou as lutas sociais e as decisões tomadas pela REAF e pelos governos nacionais. Mas, o processo de construção de uma definição regional e de readequação do arranjo normativo em cada país sugere que, no mínimo, o processo de transferência se desenvolveu em múltiplas direções, abarcando movimentos contínuos de retroalimentação. Como destacou em entrevista um ex-ministro brasileiro do desenvolvimento agrário, o desafio foi construir uma plataforma de diálogos regionais “[...] sem replicar o que cada país tem, mas trocando experiências e sendo um espaço que transcende para as instâncias internas de articulação e discussão para a constituição de políticas públicas".

A REAF constituiu um espaço de diálogo plural entre atores nacionais soberanos e zelosos de sua autonomia. É verdade que, ao confrontar as legislações e os sistemas de registro presentes em cada país, verifica-se um processo de "isomorfismo institucional" (DIMAGGIO; POWEL, 2005), sobretudo na implementação dos Registros Nacionais. Enquanto a construção de uma definição regional envolveu uma dinâmica mais intrincada de negociação e construção de entendimentos, para a operacionalização dos registros os países imitaram algumas opções desenvolvidas nos demais (sobretudo no Brasil), não porque foram forçados, mas porque acreditaram que aquelas opções eram benéficas ao seu próprio contexto, desde que cuidadosamente readaptadas. $\mathrm{O}$ resultado deste processo foi o contínuo aprimoramento dos instrumentos de identificação dos agricultores e de suas organizações coletivas, mas também das políticas públicas no interior de cada Estado.

O principal desafio continua sendo o manejo da heterogeneidade social. O espaço constituído pela REAF conseguiu para dar voz a uma miríade de grupos sociais que habitam o meio rural latinoamericano. Ali eles encontraram condições para ampliar suas lutas por reconhecimento para a escala regional. No entanto, a flexibilização dos arranjos normativos para dar conta das especificidades destes grupos ainda é objeto de tensão, assim como a readequação das políticas públicas. Hoje, a REAF contorna esta tensão acentuando uma ideia de "agricultura familiar, campesina e indígena", o que favorece o diálogo com os movimentos sociais, sobretudo a Via Campesina, mas ainda não repercute inteiramente para dentro dos países. Ademais, o ingresso de novos países na REAF, principalmente do "mundo andino", deve complexificar ainda mais este cenário, talvez reabrindo uma rodada de discussões sobre a construção sociopolítica que se afirmou em torno da ideia de agricultura familiar. A análise deste processo será objeto para a continuidade das pesquisas. 


\section{REFERÊNCIAS}

ÁLVAREZ, M. F. T. La agricultura familiar en Uruguay: entre dos proyectos contrapuestos. In: SABOURIN, E.; SAMPER, M.; SOTOMAYOR, O. Políticas públicas y agriculturas familiares en América Latina y el Caribe: balance, desafíos y perspectivas. Santiago, Chile: CEPAL, 2014. p. 275-297.

BRASIL. Ministério do Desenvolvimento Agrário. Manual do agente emissor de Declaração de Aptidão ao Pronaf. Versão 1.0. Brasília, 2014.

CARVALHO, P. D. Ação coletiva transnacional e o Mercosul: organizações da sociedade civil do Brasil e do Paraguai na construção da Reunião Especializada sobre Agricultura Familiar (REAF). 2011. Dissertação (Mestrado em Ciência Política) - Universidade de Brasilia, Brasília, 2011.

CRAVIOT'TI, C. Los enfoques centrados en las practicas de los productores familiares. Revista Internacional de Sociología, v.70, n. 3, p. 643-664, 2012.

DIMAGGIO, P.; POWEL, W. A gaiola de ferro revisitada: isomorfismo institucional e racionalidade coletiva nos campos organizacionais. RAE - Revista de Administração de Empresas, v. 45, n. 2, 2005.

DOLOWITZ, D.; MARSH, D. Learning from abroad: the role of policy transfer in contemporary policy-making. Governance: International Journal of Policy and Administration, v. 13, n. 1, 2000.

ELLIS, F. Peasant economics: farm households and agrarian development. Cambridge: Cambridge University Press, 1988.

FUNDO INTERNACIONAL DE DESENVOLVIMENTO AGRÍCOLA (FIDA). Medidas adoptadas en los cuatro países fundadores del Mercosur, vinculadas a debates $y$ recomendaciones formuladas por la REAF. Montevideo: Programa FIDA Mercosul, 2013.

GRISA, C. As ideias na produção de políticas públicas: a contribuição da abordagem cognitiva. In: BONNAL, P.; LEITE, S.P. (Org.). Análise comparada de políticas agrícolas: uma agenda em transformação. Rio de Janeiro: Editora Mauad, 2011. p. 93-138.

GRISA, C.; SCHNEIDER, S. (Org.). Políticas públicas de desenvolvimento rural no Brasil. Porto Alegre: UFRGS, 2015. 
JUÁREZ, P. et al. Argentina: políticas de agricultura familiar y desarrollo rural. In: SABOURIN, E.; SAMPER, M.; SOTOMAYOR, O. Políticas públicas y agriculturas familiares en América Latina y el Caribe. Santiago, Chile: CEPAL, 2014. p. 51-74.

KECK, M.; SIKKINK, K. Activists beyond borders: advocacy networks in international politics. Ithaca/London: Cornell University, 1998.

LATTUADA, M.; NOGUEIRA, M. E.; URCOLA, M. Tres décadas de desarrollo rural en la Argentina: continuidades y rupturas de intervenciones públicas en contextos cambiantes 1984-2014. 1. ed. Buenos Aires: Teseo; Universidad Abierta Interamericana, 2015.

MAHONEY, J. Path-dependent explanations of regime change: Central America in comparative perspective. Studies in Comparative International Development, v. 6, n. 1, 2001.

MIELITZ NETTTO, C. G. A. A política agrícola brasileira, sua adequação e sua funcionalidade nos vários momentos do desenvolvimento nacional. In: BONNAL, P.; LEITE, S. P. (Org.). Análise comparada de políticas agrícolas: uma agenda em transformação. 1. ed. Rio de Janeiro: CIRAD / Mauad X, 2011. p. 221-251.

NEVES, D. P. Agricultura familiar e o claudicante quadro institucional. In: LOPES, E.S.; MOTA, D.; SILVA, T.M. (Org.). Desenvolvimento rural e transformações na agricultura. Aracaju: Universidade Federal de Sergipe/ EMBRAPA, 2002. p. 131-159.

NIEDERLE, P. A.; FIALHO, M. A. V.; CONTERATO, M. A. (Ed.). A pesquisa sobre agricultura familiar no Brasil. Revista de Economia e Sociologia Rural, v. 52, n. esp. Agricultura Familiar, 2014.

PICOLOTTO, E.L. Os atores da construção da categoria agricultura familiar no Brasil. Revista de Economia e Sociologia Rural, v. 52, p. 63-84, 2014.

PIÑERO, D. Caracterización de la producción familiar. Montevideo, 2005. (Não publicado)

.; CARDELLAIC, J. Producción familiar y agronegocios: dos modelos en conflicto. Nueva Época, n. 10, p. 187-206, 2014.

PROGRAMA FIDA MERCOSUL - CLAEH. Institucionalidad responsable por la agricultura familiar y las políticas públicas diferenciadas em el Mercosur: marco de actuación de la REAF. Montevideo: Programa FIDA Mercosul, 2015. 
RADAELLI, C. Policy Narratives in the European Union: The Case of Harmful Tax Competition. Working Paper RSC, n. 34. European University Institute, 1998.

RAMOS, A. et al. El desarrollo institucional de la agricultura familiar en el MERCOSUR: La experiencia de la REAF. In: SALCEDO, S.; GUZMÁN, L. (Ed.). Agricultura Familiar en América Latina y el Caribe: Recomendaciones de Política. Santiago: FAO, 2014. p. 473-485.

REUNIÓN ESPECIALIZADA SOBRE AGRICULTURA FAMILIAR (REAF). 10 años cambiando realidades. REAF 10 años. 2014.

Primer Ciclo REAF. Reunión Especializada sobre Agricultura Familiar del MERCOSUR. Brasília: MDA/FIDA, 2006.

Informe sobre los registros nacionales de la agricultura familiar em el MERCOSUL. XXII REAF, Assunção, 2015.

RIELLA, A. Las Organizaciones Rurales y el proceso de Integración Regional. Revista de Ciencias Sociales, v. 20, n. 15, p. 75-86, 2002.

SABOURIN, E.; SAMPER, M.; SOTOMAYOR, O. Políticas públicas y agriculturas familiares en América Latina y el Caribe: balance, desafíos y perspectivas. Santiago: Nações Unidas, 2014.

SCHNEIDER, S; CASSOL, A. P. Diversidade e heterogeneidade da agricultura familiar no Brasil e algumas implicações para políticas públicas. Cadernos de Ciência \& Tecnologia, v. 31, p. 227-263, 2014.

SGANGA, F.; CABRERA, S.; GONZALEZ, M. Estado de situación del Registro de Productores Familiares como herramienta para la aplicación de políticas públicas para el desarrollo rural. Anuario OPYPA/MGAP2013. Montevideo: MAGP, 2013. 